\title{
Diversity and Plasticity of Sex Determination and Differentiation in Fishes
}

\author{
Y. Kobayashi ${ }^{a, b} \quad$ Y. Nagahama ${ }^{c}$ M. Nakamuraa, d \\ a Tropical Biosphere Research Center, Sesoko Station, University of the Ryukyus, Motobu, ${ }^{b}$ Ushimado Marine \\ Institute, Faculty of Science, Okayama University, Ushimado, ' Institution for Collaborative Relations, Ehime \\ University, Matsuyama, ${ }^{d}$ Ocean Exposition Commemorative Park Management Foundation, Motobu, Japan
}

\section{Key Words}

Gobiid fish $\cdot$ Gonadal sex differentiation $\cdot$ Sex change $\cdot$ Sex

determination · Tilapia $\cdot$ Wrasse

\section{Abstract}

Among vertebrates, fishes show an exceptional range of reproductive strategies regarding the expression of their sexuality. Fish sexualities were categorized into gonochorism, synchronous/sequential hermaphrodite, or unisexual reproduction. In gonochoristic fishes, sex is determined genetically or by environmental factors. After sex determination, the gonads are differentiated into ovary or testis, with the sex remaining fixed for the entire life cycle. In contrast, some sequential hermaphrodite fishes can change their sex from male to female (protandrous), female to male (protogynous), or serially (bi-directional sex change) in their life cycle. In many cases, sex change is cued by social factors such as the disappearance of a male or female from a group. This unique diversity in fishes provides an ideal animal model to investigate sex determination and differentiation in vertebrates. This review first discusses genetic-orientated sex determination mechanisms. Then, we address the gonadal sex differ- entiation process in a gonochoristic fish, using an example of the Nile tilapia. Finally, we discuss various types of sex change that occur in hermaphrodite fishes.

Copyright $\odot 2012$ S. Karger AG, Basel

Sex determination leads to a binary fate choice of the sexual characteristics in an organism. In almost all vertebrates, sexual reproduction requires 2 sexes (males and females) to maintain variation and survival. Hence, sex determination and differentiation, which develop in either the ovary or testis, is one of the most important processes for species survival. However, sex determination mechanisms vary greatly among taxa [Devlin and Nagahama, 2002; Desjardins and Fernald, 2009; Guerrero-Estévez and Moreno-Mendoza, 2010].

With over 30,000 species, teleost fishes are the largest group of vertebrates [Nelson, 2006]. Fishes exhibit a remarkable variety of sexuality [Atz, 1964]. The sexuality can be described either as gonochorism or hermaphroditism; details are given below [de Mitcheson and Liu, 2008]. The only known exceptions are unisexual species such as Poecilia formosa [Dries, 2003]. Many teleosts are

\section{KARGER \\ Fax +4161306 1234 \\ E-Mail karger@karger.ch}

www.karger.com
(C) 2012 S. Karger AG, Basel

$1661-5425 / 13 / 0073-0115 \$ 38.00 / 0$

Accessible online at:

www.karger.com/sxd
Yasuhisa Kobayashi

Ushimado Marine Institute (UMI)

Faculty of Science, Okayama University

130-17 Kashino, Ushimado, Setouchi, Okayama 701-4303 (Japan)

Tel. +81 86934 5210, E-Mail yasu_cob@amber.plala.or.jp 
gonochoristic where individuals develop as males or females only and retain the same sex throughout their life span. In many gonochoristic fishes, sex determination is genetic, i.e. males and females have different alleles or even different genes that specify their sexual morphology [Devlin and Nagahama, 2002]. In other cases, sex is determined by environmental variables such as temperature, $\mathrm{pH}$, social condition, and salinity [Baroiller et al., 2009]. Alternatively, many teleosts exhibit natural hermaphroditism where an individual changes from one sex to the other during adulthood. This unique feature of sexuality is limited only to fishes among the vertebrates. Several different types of hermaphrodites have been described [Devlin and Nagahama, 2002; Frisch, 2004; de Mitcheson and Liu, 2008]. Some teleosts have gonads containing both mature ovaries and testes (synchronous hermaphroditism). In sequential hermaphroditism, some fishes change sex from male to female (protandrous sex change), others change from female to male (protogynous sex change), and a few change sex in both directions multiple times (bi-directional sex change). In many cases of sequential hermaphroditism, sex change is controlled by social cues such as the disappearance of a male or female from a group. Thus, the mechanisms of sex determination and differentiation in fishes are highly diverse and plastic, differing from those of other higher vertebrates [Desjardins and Fernald, 2009]. Hence, fishes are a very interesting group among the vertebrates for the study of sex determination and differentiation.

Our major interest is to uncover the physiological mechanisms that regulate the sex change processes in hermaphrodite fishes. However, it is necessary to understand the process of sex determination and differentiation in well-studied gonochoristic fishes (medaka and tilapia) to elucidate the complicated mechanisms of sexchanging fishes. Therefore, in this review we first describe the mechanisms of sex determination in gonochoristic fishes. We then summarize the process and regulation of gonadal sex differentiation in tilapia via sex steroid hormones and other regulators. Finally, we use 4 different species as examples to describe our recent work on sexchanging fishes. This review intends to highlight sexual plasticity in fishes related to sex determination. For detailed information on other aspects of sex determination and differentiation in fishes, particularly genetics, please refer to the recent reviews by Nagahama [2005] and PaulPrasanth et al. [2011].

\section{Sex Determination in Gonochoristic Fishes}

In gonochoristic fishes, sex determination can be genetic, environmental, or a combination of both [Devlin and Nagahama, 2002; Volff et al., 2007; Penman and Piferrer, 2008]. In this section, we outline genetic sex determination in gonochoristic fishes. The review by Baroiller et al. [2009] provides information on environmental sex determination in fishes.

In almost all mammals, the heterogametic sex is male which is propagated by the inheritance of a Y chromosome. The first discovery of a single gene, $S R Y$ (sex determining region $\mathrm{Y}$ ), on the $\mathrm{Y}$ chromosome and its subsequent functional analysis has demonstrated that $S R Y$ is necessary and sufficient to initiate testicular development [Koopman et al., 1990; Sinclair et al., 1990]. However, the SRY gene is not found in any other class that uses the system of genetic sex determination [Capel, 2000; Marshall Graves, 2002]. This observation indicates that sex determination mechanisms show no clear evolutionary conservation between phyla and that the sex determination system in other animals has arisen independently [Raymond et al., 1998].

The second sex determination gene in vertebrates was identified in the Japanese medaka, Oryzias latipes, which has a male heterogametic (XX-XY) system [Matsuda et al., 2002; Nanda et al., 2002]. This gene was named as $d m y$ or $d m r t 1 b$ as it was found to be a duplicate copy of the well-conserved downstream gene dmrtl (doublesex and mab-3 related factor 1) on the Y chromosome, associated with vertebrate testicular differentiation [FergusonSmith, 2007; Piferrer and Guiguen, 2008]. The analysis of loss and gain of function of this gene proved that $d m y$ is necessary and sufficient for initiating testicular differentiation [Paul-Prasanth et al., 2006; Matsuda et al., 2007]. However, the molecular mechanism of Dmy, especially the target gene, remains largely unknown. Dmy is also found in Oryzias curvinotus which is most closely related to O. latipes [Nanda et al., 2002; Matsuda, 2003]. However, $d m y$ was not found in other fishes or other Oryzias species [Matsuda et al., 2007; Kondo et al., 2009]. This finding suggests that even this sex-determining gene exhibits extensive diversity among fishes.

In other fishes that exhibit genetic sex determination (such as Nile tilapia, zebrafish, stickleback, salmonid fishes, guppy, and fugu), extensive search efforts to identify the sex determination gene have been carried out [Peichel et al., 2004; Kikuchi et al., 2007; Tripathi et al., 2009; Ser et al., 2010]. As a result, several candidate genes for sex determination and the sex-determining locus 
Fig. 1. Schematic representation of the gonadal sex differentiation process in males (XX) and females (XY) of the Nile tilapia, Oreochromis niloticus. a Gonad at 3 days post hatch (dph). Arrowheads indicate germ cells. b XX gonad of tilapia at $20 \mathrm{dph}$, just after ovarian differentiation. Arrows show the elongation of 2 somatic ridges for the formation of the ovarian cavity. Note the presence of cysts of meiotic prophase germ cells $(\mathrm{O})$ and clusters of steroid-producing cells (SPC, arrowheads) in the vicinity of a blood vessel (BV). c XY gonad of tilapia just after testicular differentiation (25 dph). A slit-like structure indicating the formation of an efferent duct (ED) is visible in the stromal tissue. Note the germ cells (arrows) that remain at the gonial stage. The arrowhead indicates the SPC. dXX gonad at $35 \mathrm{dph}$. e XY gonad at $70 \mathrm{dph}$. Bars indicate $20 \mu \mathrm{m}$, except for $\mathbf{b}(30 \mu \mathrm{m})$. P450scc: cholesterol side-chain cleavage cytochrome P450; $3 \beta$-HSD: $3 \beta$-hydroxysteroid dehydrogenase; P450c17: cytochrome P450 17 $\alpha$-hydroxylase/17,20 lyase; P450arom: cytochrome P450 aromatase.

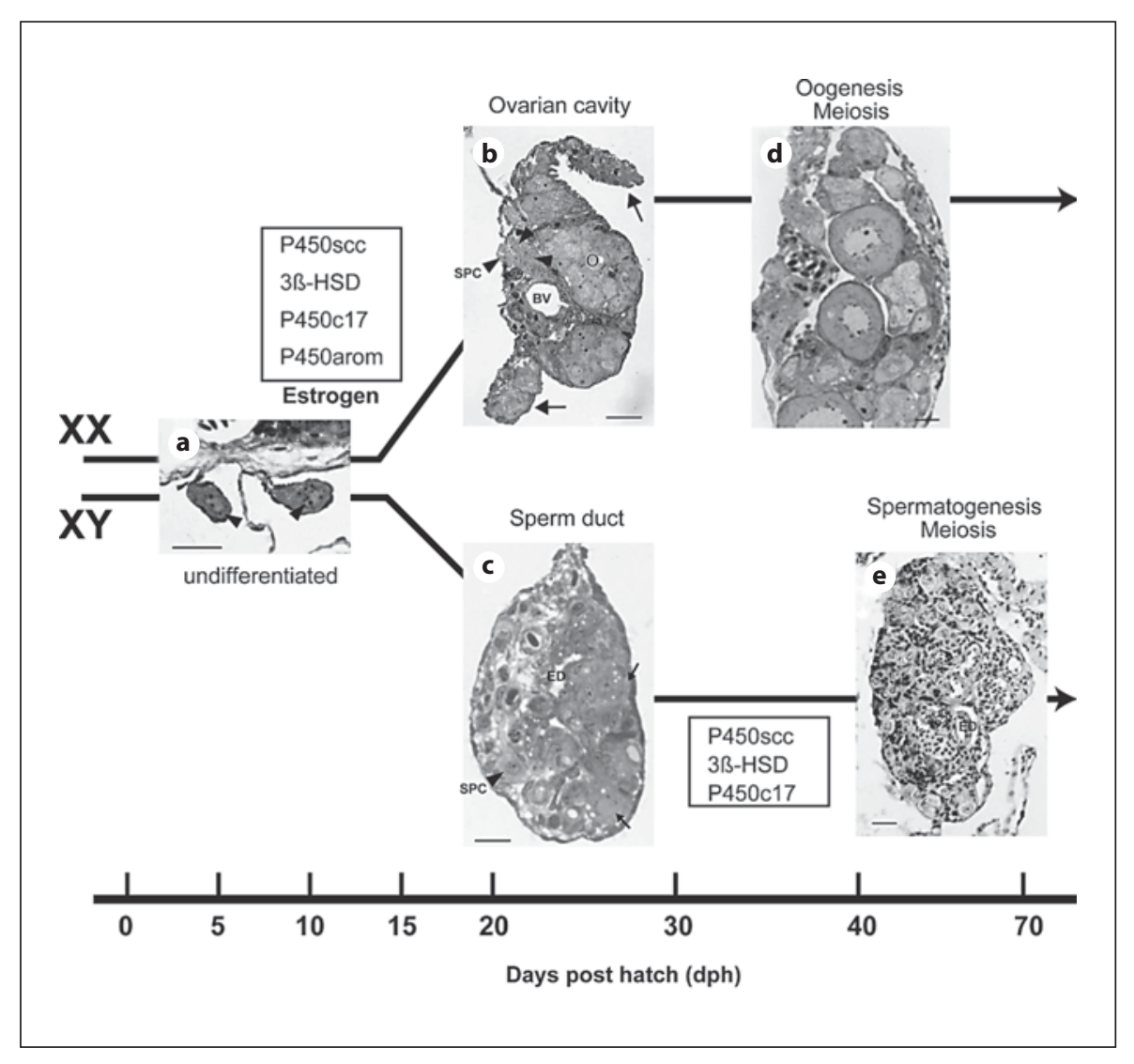

have been identified using several different methods of analysis, such as quantitative trait loci (QTL) analysis, transcriptome analysis, and complete genomic analysis. Among these studies, the anti-Müllerian hormone $(\mathrm{amh})$ was mapped within an autosomal sex-determining QTL in tilapia [Shirak et al., 2006]. However, experimental evidence clarifying the function of $a m h$ and other candidate genes in sex determination is lacking, yet the identification of additional sex determination related genes is critical to improve our understanding of genetic sex determination in vertebrates.

\section{Gonadal Sex Differentiation in Fishes}

To investigate the process of gonadal differentiation, a prefixed genetic sex population of experimental animals is convenient for the study. The Nile tilapia, Oreochromis niloticus, is a gonochoristic teleost fish with a XX/XY sexdetermining system. All genetic females (XX) and males (XY) may potentially be produced using sperm obtained from sex-reversed males (XX) or super males (YY), respectively. Therefore, tilapia happens to be an excellent model to study gonadal sex differentiation.

Figure 1 shows gonadal differentiation in tilapia. Morphological sexual dimorphism during gonadal differentiation comprises changes in germ cell number. On the day of hatching, primordial germ cells (PGCs), which are morphologically distinguishable from somatic cells, are located in the outer layer of the lateral plate mesoderm around the hindgut. At 3 days post hatching (dph), PGCs are located in the gonadal anlagen after the formation of the coelomic cavity in the lateral plate mesoderm, rather than actively migrating (fig. 1a). After $9 \mathrm{dph}$, the XX female germ cells proliferate (mitosis), whereas the germ cell numbers do not change from 9-14 dph in XY male gonads [Nakamura 1998; Kobayashi et al., 2000, 2002]. However, the morphogenesis of somatic tissues in both $\mathrm{XX}$ and XY gonads is not apparent until several days later. The first signs of gonadal sex differentiation appear at 20 and $25 \mathrm{dph}$, with the ovarian cavity or the intratesticular efferent duct appearing in the XX and XY gonads, 
respectively (fig. 1b, c). Meiosis becomes apparent in the ovaries between 25 and $30 \mathrm{dph}$ (fig. 1d), while spermatogenesis is initiated between 50 and $70 \mathrm{dph}$ (fig. 1e) [Nakamura et al., 1998; Kobayashi et al., 2000; D'Cotta et al., 2001].

\section{Role of Sex Steroid Hormones and Other Regulators for Gonadal Sex Differentiation}

Low doses of exogenous sex steroid hormones (androgens or estrogens) were administered before sexual differentiation when functional sex reversal from one sex toward the opposite sex was first achieved in medaka [Yamamoto, 1958]. This method identified a wide variety of fish species wherein sex steroid hormones have an important role in gonadal differentiation [Devlin and $\mathrm{Na}$ gahama, 2002; Guiguen et al., 2010]. However, there is no direct experimental evidence clarifying whether endogenous sex steroid hormones play an essential role in the initiation of gonadal differentiation in fishes. Therefore, our research group conducted immunohistochemical observations on the gonadal sex differentiation process in tilapia by using 4 steroidogenic enzymes (P450scc: cholesterol side-chain cleavage cytochrome P450;3 $\beta$ HSD: $3 \beta$-hydroxysteroid dehydrogenase; P450c17: cytochrome P450 17 $\alpha$-hydroxylase/17,20 lyase; P450arom: cytochrome $\mathrm{P} 450$ aromatase) which are essential for the biosynthesis of all major sex steroid hormones, including androgens and estrogens [Nagahama, 1994]. This experimental approach revealed that only the gonads of genotypic females at 7-10 dph have immunopositive cells for all antibodies before sex differentiation (fig. 1) [Strüssmann and Nakamura, 2002; Kobayashi et al., 2003]. Specifically, immunopositive cells of P450arom, which is the critical enzyme for the biosynthesis of estradiol-17 $\beta$ from testosterone, were observed near the blood vessels in $7 \mathrm{dph}$ XX gonads [Sakai et al., 2008]. Molecular biological studies also showed that P450arom mRNA (cyp19a1a) was first detected at $5 \mathrm{dph}$ prior to morphological gonadal sex differentiation in XX gonads and then increased rapidly from 7 dph [Sudhakumari et al., 2005; Ijiri et al., 2008]. In addition, the pharmacological inhibition of aromatase activity, following treatment with specific inhibitors (aromatase inhibitor, AI) during gonadal sex differentiation, caused the masculinization of genotypic females of tilapia [Guiguen et al., 1999; Ruksana et al., 2010]. Similar masculinization effects caused by AI treatment were observed in Chinook salmon [Piferrer et al., 1994], rainbow trout [Guiguen et al., 1999], and the
Japanese flounder [Kitano et al., 2000]. These results strongly indicate that endogenous estrogen is the natural inducer of ovarian differentiation in gonochoristic teleosts. Therefore, detailed examination of factors or genes that are involved in the regulation of P450arom (cyp19a1a) expression is imperative to understand the molecular mechanisms that precede ovarian differentiation.

Forkhead transcriptional factor 2 (Foxl2) is a member of the winged helix/forkhead group of proteins [Baron et al., 2005]. Many studies on the ontogenic expression of Foxl2 have been carried out in vertebrates [Baron et al., 2005; Yao, 2005]. These studies revealed Foxl2 as one of the earliest markers of ovarian differentiation in vertebrates [Schlessinger et al., 2010; Raghuveer et al., 2011]. As in mammals, the mRNA of P450arom and Foxl2 were found to be co-localized in the ovaries of adult medaka [Nakamoto et al., 2006], tilapia [Wang et al., 2004], and flounder [Yamaguchi et al., 2007]. In addition, these markers were found in the immature gonads of chicken [Govoroun et al., 2004] and frogs [Oshima et al., 2008] just after initiation of ovarian differentiation. In tilapia, molecular analysis revealed that Foxl2 directly binds to the promoter region of the cyp19ala (P450arom) gene in addition to interacting with the Ad4 Binding Protein/Steroidogenic Factor 1 (Ad4BP/SF-1). Wang et al. [2007] also revealed that the overexpression of foxl2 in XY male larvae leads to sex reversal. Hence, we concluded that Foxl2 and P450arom are essential for ovarian differentiation [Wang et al., 2007].

In contrast to females (XX gonad), genetic males (XY) have weakly immunopositive cells for 3 steroidogenic enzymes; they appear only after the somatic differentiation of the testis has taken place. Furthermore, P450arompositive cells could not be identified in these males, even after the onset of spermatogenesis (fig. 1) [Nakamura et al., 1998]. In addition, the expression of cytochrome $P 450$ $11 \beta$-hydroxylase, which is a critical enzyme in the production of a teleost potent androgen, 11-ketotestosterone, was not detected in either XX or XY gonads at 5-25 dph [Ijiri et al., 2008]. Hence, in tilapia the absence of endogenous estrogens rather than the presence of androgens seems to be correlated with testicular differentiation. Indeed, the initiation of testicular differentiation is not required for the production of androgens in rainbow trout [Vizziano et al., 2007].

To date, $d m r t 1$ is known to be involved in the testicular differentiation of teleosts [Koopman and Loffler, 2003; Raghuveer and Senthilkumaran, 2009; Herpin and Schartl, 2011] and other vertebrates [Ferguson- 
Smith, 2007; Matson et al., 2011]. Dmrt1 was detected in the gonial germ cells of tilapia and in the surrounding cells (Sertoli precursor cells) of XY larvae, specifically before the appearance of any signs of morphological sex differentiation. In mature fish, Dmrtl was only localized to the Sertoli and epithelial cells of the intratesticular efferent duct in the testes and was undetectable in the ovaries [Kobayashi et al., 2004; Raghuveer and Senthilkumaran, 2009]. Interestingly, Dmrt1 was newly expressed in the somatic cells of androgen-induced sex reversal ovaries. In addition, estrogen treatment for XY larvae suppressed the expression of Dmrtl [Kobayashi et al., 2004; Raghuveer et al., 2005]. Recently, in vitro and in vivo functional analyses revealed that Dmrt1 probably induces testicular differentiation by its direct blocking action on estrogen production [Wang et al., 2010].

Here, we have presented the regulators for the process of gonadal sex differentiation, such as foxl2 and dmrt1. However, the upstream factors that control these genes have not been identified. Recently, in tilapia [Ijiri, unpublished data] and medaka [Shibata et al., 2010], the same homologous gene (gonadal soma-derived growth factor, $g s d f$ ) was identified by using a global screening method to identify unknown factors that are important for testicular differentiation. Gsdf, which is a new member of the TGF- $\beta$ superfamily, was identified in rainbow trout as the gene that is expressed in genital ridge somatic cells surrounding the PGCs during embryogenesis [Sawatari et al., 2007]. Trout $g s d f$ is also expressed in both granulosa and Sertoli cells during the later stages of gonadal development. Moreover, recombinant $g s d f$ enhances the proliferation of PGCs and spermatogonia. The orthologous genes of $g s d f$ are well conserved among teleosts but not in tetrapods [Sawatari et al., 2007; Gautier et al., 2011]. In the undifferentiated gonad of XY tilapia at $5 \mathrm{dph}$, the $g s d f$ mRNA was strongly expressed in somatic cells surrounding PGCs. In the differentiated testis, Gsdf signals were only detected in somatic cells surrounding type A spermatogonia. In contrast, no detectable signal was observed in the undifferentiated XX gonad or ovary. In adult medaka, Gsdf was localized in Sertoli cells surrounding spermatogonia in the testis and in granulosa cells surrounding oogonia and pre-vitellogenic oocytes in the ovary [Shibata et al., 2010]. Interestingly, Gsdf is only co-localized with Dmy in somatic cells of the primordial gonads of genetic males at 6 dph [Shibata et al., 2010]. Overall, these results indicate that Gsdf might be involved in early testicular differentiation of tilapia and medaka. Hence, future inves- tigations aiming towards understanding the physiological roles of Gsdf in testicular sex differentiation will be rewarding.

\section{Sequential Hermaphrodite Fishes (Sex-Changing Fishes)}

Hermaphroditism has been documented in about 2\% of all extant fish species [Avise and Mank, 2009]. Sequential hermaphrodite (sex-changing) species have been recorded in 27 of 448 families across 7 orders of fishes, many of which have found a niche in coral reefs; however, most research has been focused only on 5 families [de Mitcheson and Liu, 2008]. In these fishes, gonadal sex redifferentiation was observed during sex change in adulthood. Thus, sex-changing fishes are ideal models to investigate gonadal differentiation in vertebrates.

In this review, we restrict our discussion to 4 sexchanging species: the three-spot wrasse (Halichoeres trimaculatus) and saddleback wrasse (Thalassoma duperrey) for protogynous sex change, the yellow tail clownfish (Amphiprion clarkii) for protandrous sex change, and the Okinawa rubble gobiid fish (Trimma okinawae) for bidirectional sex change. In this section, we primarily focus on studies related to gonadal sex change. However, changes also occur in organs other than the gonads, such as the brain. For more information on sex change induced effects on fish brains we refer the readers to peruse the review by Godwin [2010].

\section{Protogynous Sex Change in Wrasse}

Wrasses are the major group of species that display protogynous sex change. Individuals of this species initially mature as either males or females. Under appropriate social conditions, initial phase (IP) males and females change to terminal phase (TP) males. While IP males only change their reproductive status, IP females change their sexuality and gonadal phenotype [Hourigan et al., 1991]. The ovaries of females, which have no detectable testicular tissues, are fully restructured into functional testis during sex change [Nakamura et al., 1989; Hourigan et al., 1991]. In saddleback wrasse, vitellogenic oocytes degenerate at the initiation of sex change and are ingested by macrophagous cells. This stage is accompanied by a rapid drop in plasma estradiol-17 $\beta$ levels (fig. 2). In contrast, 11-keto testosterone gradually increases in parallel to the increase of testicular tissues [Nakamura et al., 1989]. Therefore, rapidly decreasing estrogen levels rather than androgen increases are probably important 
for the initiation of sex change. To determine the involvement of endogenous estrogen in the gonadal sex change of wrasse, our research group suppressed aromatase activity via the administration of AI in three-spot wrasse females. Just 5 days of AI treatment induced complete female-to-male sex change, with the gonads of AI-induced females being similar to those of normal males [Nozu et al., 2009]. In addition, we induced reversal of sex change (male-to-female) by treating adult IP males with a high dose of estrogen [Kojima et al., 2008]. These results indicate that the decline in plasma estrogen is a key factor for gonadal sex change in addition to the maintenance of testis formation in wrasse. This finding was in accordance with another study on a sex-changing fish species [Gardner et al., 2005]. Therefore, acquisition of information about the regulation of P450arom (cyp19a1a) transcription is important for understanding the physiological mechanism of sex change in wrasse. Alternatively, important regulators for testicular differentiation (Dmrtl and Gsdf) may be involved in the proliferation of spermatogonia in the early stages of sex change [Horiguchi et al., in preparation] as found in other vertebrates.

\section{Protandrous Sex Change in Clownfish}

Clownfish (e.g. Amphiprion species) are common inhabitants of tropical coral reefs where they avoid predators by living around the stinging tentacles of sea anemones. Each clownfish group that is associated with an anemone consists of one breeding pair and 0-4 nonbreeders [Elliott and Mariscal, 2001]. A size-dominance hierarchy characterizes each group, with the female as the largest and dominant member, the male as the second largest member, and any non-breeders as smaller members of the group [Hattori, 2000]. The disappearance or death of the female leads to protandrous (maleto-female) sex change of the male fish which, in becoming female, also gains dominance [Fricke and Fricke, 1977].

Histological analysis of the gonads of clownfish has revealed that males and non-breeders possess bisexual gonads with co-existing mature testicular and immature ovarian tissues, whereas the gonads of females contain only ovarian tissues [Godwin, 1994; Nakamura et al., 1994]. During sex change, the ovarian tissues develop and the testicular tissues regress in the bisexual gonads [Godwin, 1994]. The mechanisms of this process have been studied extensively. As in other sex-changing species [Nakamura et al., 2005], gonadal sex steroid hormones, especially estrogens, are the key regulators of sex change

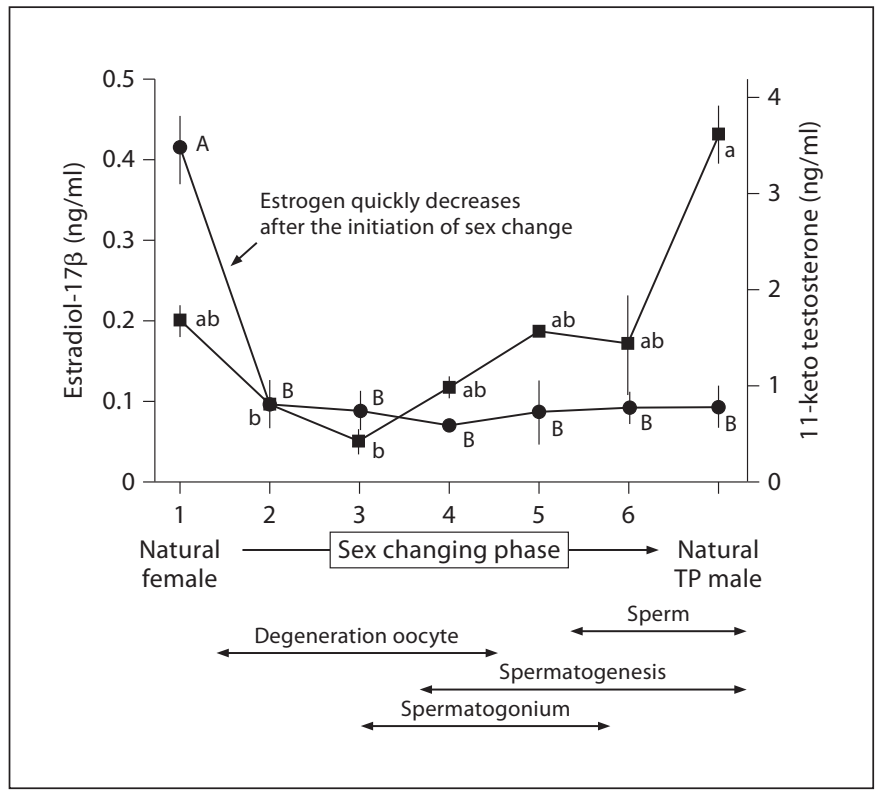

Fig. 2. Changes in the plasma levels of estradiol-17 $\beta$ (circles) and 11-keto testosterone (squares) during the sex change process of saddleback wrasse, Thalassoma duperrey. Different letters indicate significant differences. $\mathrm{X}$ axis indicates the sexual or transdifferentiation phase [Nakamura et al., 1989].

in clownfish [Godwin and Thomas, 1993; Kobayashi et al., 2010]. However, the upstream mechanisms controlling the production and activity of gonadal steroid hormones during sex change in clownfish remain largely unknown.

\section{Bi-Directional Sex Change in Gobiid Fish}

Protandrous and protogynous sex changes are generally irreversible. Thus, such sex changes only happen once in a life cycle. However, the Okinawa rubble gobiid fish, Trimma okinawae, is the first known teleost that is capable of bi-directional sex change [Sunobe and Nakazono, 1993]. This fish has a polygynous mating system in which a harem normally consists of one dominant male and one or more females [Sunobe and Nakazono, 1990]. Removal of the dominant male from the harem results in female-to-male sex change by the largest female (protogyny). If the dominant male is returned to the harem, the fish that underwent the sex change transforms back into a female again (protandry) [Sunobe and Nakazono, 1993; Manabe et al., 2007, 2008].

In aquarium experiments, when 2 females or 2 males are paired, the larger female changes its sex to male within just 5 days, while the smaller male changes to a female 


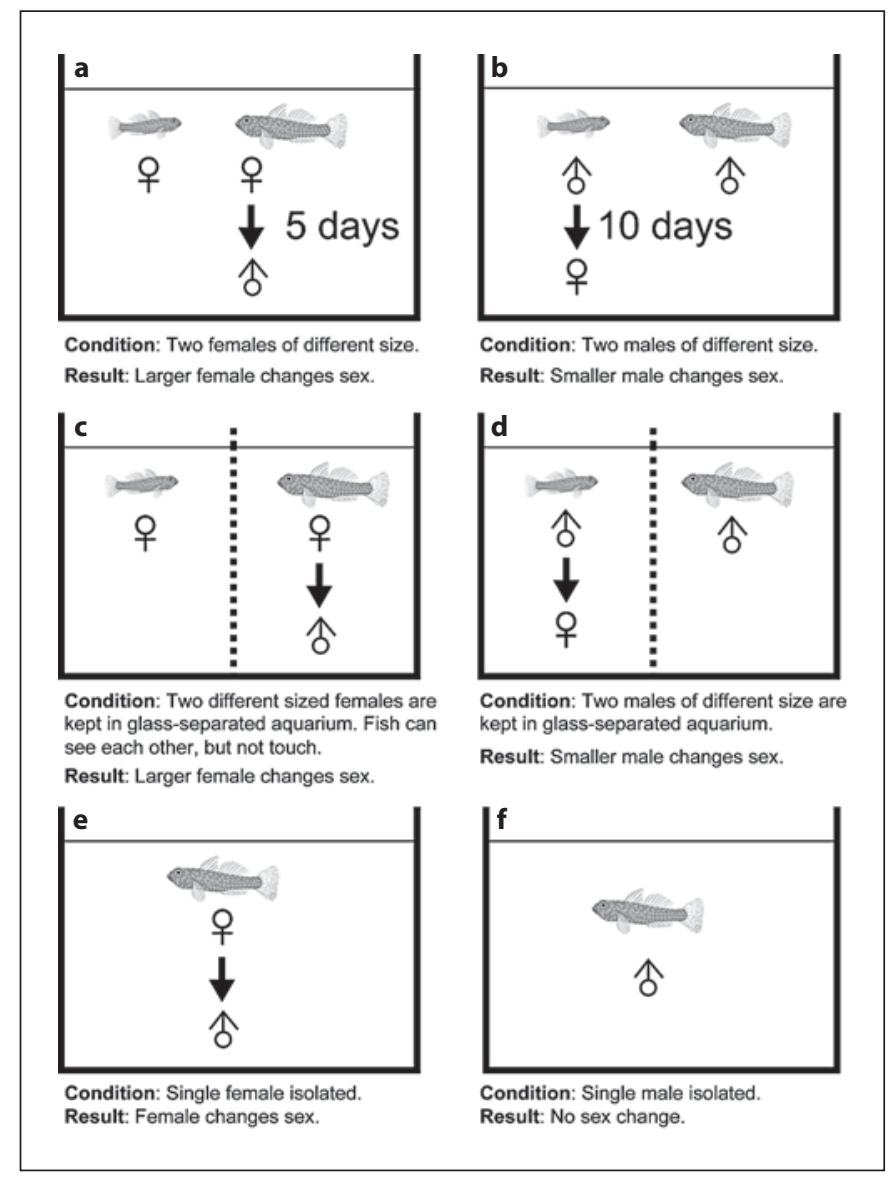

Fig. 3. Aquarium experiments for the induction of bi-directional sex change in the gobiid fish, Trimma okinawae. Two or 1 fish were isolated in an aquarium; the aquaria settings are provided in the figure. Protogynous sex change (female-to-male) was observed in a, c, and e. Protandrous sex change (male-to-female) was observed in $\mathbf{b}$ and $\mathbf{d}$. No sex change was observed in $\mathbf{f}$.

within 10 days (fig. 3). These periods and rates of sex change are fast and successful compared to other hermaphrodite teleosts [Devlin and Nagahama, 2002]. In addition, our research group isolated a single male or female in an aquarium. Protogyny sex change was induced in the isolated female, whereas sex change was not induced in the isolated male. Finally, we kept 2 females or males in one aquaria separated by glass. In this experiment, these fish changed sex in the same way as the pair in one aquarium. Thus, this species is able to determine the body size of other individuals in the group visually. These results emphasize that a social visual cue is sufficient for the initiation of sex change in this species.

Histological observations revealed that this gobiid species has ovarian and testicular tissues simultaneously

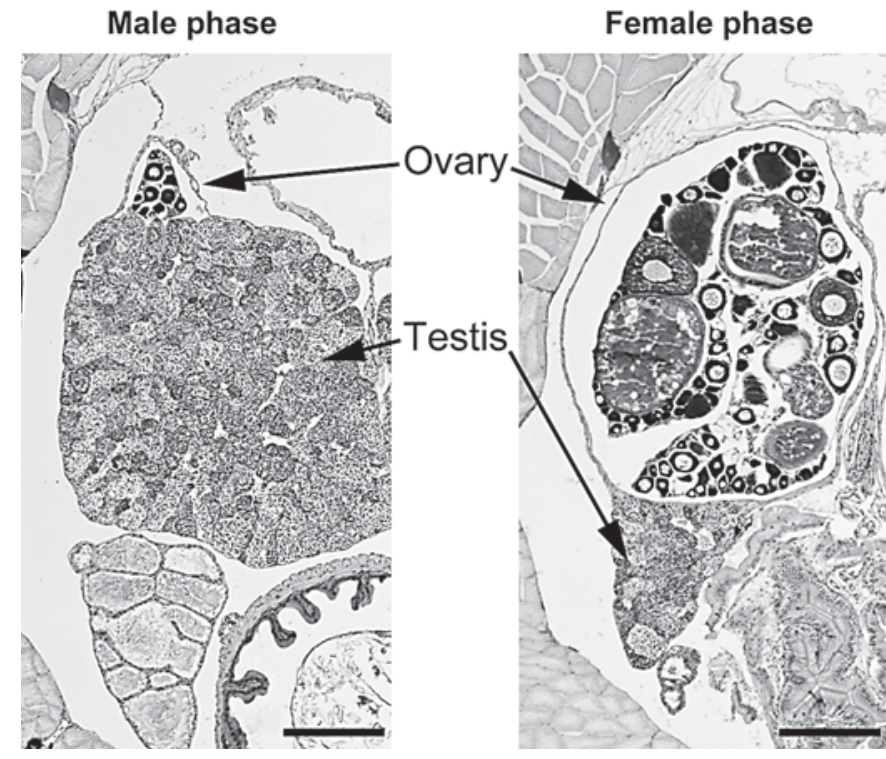

Fig. 4. Gonads of different sexual phases in the bi-directional sexchanging gobiid fish, Trimma okinawae. In the gonad of the male phase, some oocytes at the peri-nucleolar stage are visible in the ovary and active spermatogenic germ cells are visible in the testes. In the gonad of the female phase, many vitellogenic and pre-vitellogenic oocytes are visible in the ovaries, with a small testis also being present. (fig. 4) [Kobayashi et al., 2005]. In brief, this fish is equipped to adjust its social status by possessing both ovary and testis, even though only one gonad is active at any one point of time. This unique gonadal structure facilitates sex change in both directions.

We also investigated the mechanisms involved in the sex change of the gonads. The earliest observed change in the gonads was the alteration in the expression levels of gonadotropin receptors (GtHRs; FSHR and LHR) [Kobayashi et al., 2009]. The expression of GtHRs was found to be confined to the active gonad of the corresponding sexual phase. During the sex change from female to male, the ovary initially had high levels of FSHR and LHR which eventually transformed the testicular tissue in the biggest fish. The gonads started to change with the switching of GtHR expression which was discernible within $8-12 \mathrm{~h}$ of the visual cue. Our findings suggest that sex change is initiated with rapid changes in brain/sex behavior, followed by changes in the gonad which is mediated by GtHRs. Trimma okinawae is an ideal model to study the role of sex behavior with respect to initiation of sex change in response to environmental stimuli. 


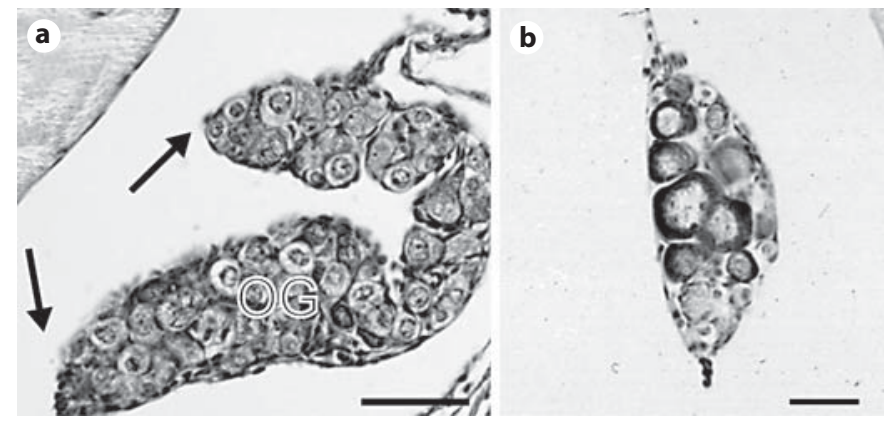

Fig. 5. Histological observation of the juvenile gonad of protogynous three-spot wrasse (a) and bi-directional sex-changing gobiid fish (b). a In three-spot wrasse, the gonad first differentiated to the ovary. Picture shows the process of formation of the ovarian cavity by the extension of both tips of gonads (arrows). Bar = $50 \mu \mathrm{m} ; \mathrm{OG}=$ oogonia. $\mathbf{b}$ In the juvenile phase of gobiid fish, some oocytes at the peri-nucleolar stage and undifferentiated germ cells can be seen underneath the swim bladder. Bar $=20 \mu \mathrm{m}$.

\section{Gonadal Differentiation in Sex-Changing Fishes}

Since only social cues induce gonadal sex change, hermaphrodite sex-changing fishes might have gonads with higher sexual plasticity than gonochoristic fishes. However, to date, information about gonadal differentiation in sex-changing fishes remains limited. This is because the larvae of these fishes are weak and difficult to breed, except for protogynous grouper, protogynous clownfish, and black porgy. In grouper, the gonads of all individuals differentiate directly into ovaries at approximately $47 \mathrm{dph}$ [Murata et al., 2009]. Similarly, all undifferentiated gonads of clownfish [Miura et al., 2008] and black porgy [Lee et al., 2001] first differentiate into immature ovaries. Then, testicular tissues appear among ovarian tissues and finally form bisexual gonads with both ovarian and testicular tissues. Although ontogeny was not achieved, we histologically observed the juvenile gonads of protogynous threespot wrasse and bi-directional sex-changing gobiid fishes which were obtained from nature. In three-spot wrasse, some juvenile fishes possess an immature ovary (fig. 5a). Subsequently, this immature ovary differentiates into a mature ovary (IP females) or testis (IP males). These processes are similar to 'juvenile hermaphroditism' [Maack and Segner, 2003]. In addition, all experimental juveniles of bi-directional sex-changing gobiid fishes only have immature ovaries (fig. 5b). These observations imply that ovarian differentiation may be the primary status in all sequential hermaphrodite species. To test this hypothesis, information about the gonadal differentiation process in other sex-changing fishes is required.

\section{Conclusion}

In this review, we discussed sex determination, differentiation, and sex change in fishes related to our recent studies. Dmy, which is the second identified sex determination gene in vertebrates, has only been isolated in 2 Oryzias species [Matsuda et al., 2007; Kondo et al., 2009]. This observation indicates that the genetic mechanisms differ in non-mammalian vertebrates. However, the morphological process of gonadal sex differentiation is conserved in vertebrates. Our studies revealed that estrogen and P450arom are involved in both ovarian differentiation and sex change in fishes. In contrast, the role of androgens for testicular differentiation is unclear but requires expression of both $d m r t 1$ and $g s d f$. It is possible that the role of $d m r t 1$ for testicular differentiation is conserved among vertebrates. In comparison, $g s d f$, which is the new key factor for the testicular differentiation, is unique to teleosts. Detailed analysis of $g s d f$ might reveal testicular differentiation through evolution.

Although exogenous steroid hormones induced sex reversal in gonochoristic fishes during gonadal sex differentiation, most vertebrates, including fishes, are thought to lose sexual plasticity in germ and somatic cells after gonadal sex differentiation. Nevertheless, conditional ablation of Foxl2 in adult female mice resulted in the transdifferentiation of granulosa cells into Sertoli cells [Uhlenhaut et al., 2009]. In addition, our recent experiments using AI confirmed that gonochoristic fishes (tilapia, zebrafish, carp, and rabbitfish) also retain sexual plasticity even in adulthood [in preparation]. These results suggest that few vertebrates do not lose sexual plasticity in germ and somatic cells during their life cycle. However, the mechanism of sexual plasticity remains largely unknown. In contrast to other vertebrates we have shown here that sex-changing fishes exhibit large sexual plasticity during their life span. Therefore, comparisons of the differences between gonochoristic and hermaphrodite fishes might provide new insights about sexual plasticity in vertebrates.

Studies about sex determination and differentiation are frequently conducted using popular model fishes (i.e. medaka, tilapia, and zebrafish). However, many questions require answers that might come from other fish models as well. Recently, access to detailed genomic information of animals by using next-generation sequencing has become easier [Zhang et al., 2011]. Therefore, the isolation of additional sex determination genes and/or downstream genes of sex determination pathways in fishes is expected in the near future. 


\section{Acknowledgment}

We are grateful to Dr. B Senthilkumaran (University of Hyderabad) for the critical reading of the manuscript. This research was financially supported by Solution Oriented Research for Sci- ence and Technology (SORST), Japan Science and Technology Corporation (JST), Ocean Exposition Commemorative Park Management Foundation, Japan Society for Promotion of Science (JSPS), and the Ministry of Education, Culture, Sports, and Technology (Project No. 23658166 and 23248034 to MN).

\section{References}

Atz JW: Intersexuality in fishes, in Armstrong $\mathrm{CN}$, Marshall AJ (eds): Intersexuality in Vertebrates Including Man, pp 145-232 (Academic Press, London 1964).

Avise JC, Mank JE: Evolutionary perspectives on hermaphroditism in fishes. Sex Dev 3:152163 (2009).

Baroiller JF, D’Cotta H, Saillant E: Environmental effects on fish sex determination and differentiation. Sex Dev 3:118-135 (2009).

Baron D, Batista F, Chaffaux S, Cocquet J, Cotinot C, et al: Foxl2 gene and the development of the ovary: a story about goat, mouse, fish and woman. Reprod Nutr Dev 45:377-382 (2005).

-Capel B: The battle of the sexes. Mech Dev 92: 89-103 (2000).

-D'Cotta H, Fostier A, Guiguen Y, Govoroun M, Baroiller JF: Aromatase plays a key role during normal and temperature-induced sex differentiation of tilapia Oreochromis niloticus. Mol Reprod Dev 59:265-276 (2001).

de Mitcheson YS, Liu M: Functional hermaphroditism in teleosts. Fish Fish 9:1-43 (2008).

Desjardins JK, Fernald RD: Fish sex: why so diverse? Curr Opin Neurobiol 19:648-653 (2009).

Devlin RH, Nagahama Y: Sex determination and sex differentiation in fish: an overview of genetic, physiological, and environmental influences. Aquaculture 208:191-364 (2002).

Dries LA: Peering through the looking glass at a sexual parasite: are Amazon mollies red queens? Evolution 57:1387-1396 (2003)

-Elliott JK, Mariscal RN: Coexistence of nine anemonefish species: differential host and habitat utilization, size and recruitment. Mar Biol 138:23-36 (2001).

Ferguson-Smith M: The evolution of sex chromosomes and sex determination in vertebrates and the key role of Dmrt1. Sex Dev 1: 2-11 (2007).

Fricke H, Fricke S: Monogamy and sex change by aggressive dominance in coral reef fish. Nature 266:830-832 (1977).

Frisch A: Sex-change and gonadal steroids in sequentially-hermaphroditic teleost fish. Rey Fish Biol Fisher 14:481-499 (2004).

- Gardner L, Anderson T, Place AR, Dixon B, Elizur A: Sex change strategy and the aromatase genes. J Steroid Biochem Mol Biol 94:395404 (2005)
Gautier A, Le Gac F, Lareyre JJ: The gsdf gene locus harbors evolutionary conserved and clustered genes preferentially expressed in fish previtellogenic oocytes. Gene 472:7-17 (2011).

Godwin J: Historical aspects of protandrous sex change in the anemonefish Amphiprion melanopus (Pomacentridae, teleostei). J Zool 232:199-213 (1994).

Godwin J: Neuroendocrinology of sexual plasticity in teleost fishes. Front Neuroendocrinol 31:203-216 (2010).

Godwin JR, Thomas P: Sex change and steroid profiles in the protandrous anemonefish Amphiprion melanopus (Pomacentridae, Teleostei). Gen Comp Endocrinol 91:144-157 (1993).

Govoroun MS, Pannetier M, Pailhoux E, Cocquet J, Brillard JP, et al: Isolation of chicken homolog of the Foxl2 gene and comparison of its expression patterns with those of aromatase during ovarian development. Dev Dyn 231:859-870 (2004).

Guerrero-Estévez S, Moreno-Mendoza N: Sexual determination and differentiation in teleost fish. Rev Fish Biol Fisher 20:101-121 (2010).

- Guiguen Y, Baroiller JF, Ricordel MJ, Iseki K, McMeel OM, et al: Involvement of estrogens in the process of sex differentiation in two fish species: the rainbow trout (Oncorhynchus mykiss) and a tilapia (Oreochromis niloticus). Mol Reprod Dev 54:154-162 (1999).

-Guiguen Y, Fostier A, Piferrer F, Chang CF: Ovarian aromatase and estrogens: a pivotal role for gonadal sex differentiation and sex change in fish. Gen Comp Endocrinol 165: 352-366 (2010).

Hattori A: Social and mating systems of the protandrous anemonefish Amphiprion perideraion under the influence of a larger congener. Austral Ecol 25:187-192 (2000).

Herpin A, Schartl M: Dmrt1 genes at the crossroads: a widespread and central class of sexual development factors in fish. FEBS J 278: 1010-1019 (2011).

Hourigan TF, Nakamura M, Nagahama Y, Yamauchi K, Grau EG: Histology, ultrastructure, and in vitro steroidogenesis of the testes of two male phenotypes of the protogynous fish, Thalassoma duperrey (Labridae). Gen Comp Endocrinol 83:193-217 (1991).
Ijiri S, Kaneko H, Kobayashi T, Wang DS, Sakai F, et al: Sexual dimorphic expression of genes in gonads during early differentiation of a teleost fish, the Nile tilapia Oreochromis niloticus. Biol Reprod 78:333-341 (2008).

Kikuchi K, Kai W, Hosokawa A, Mizuno N, Suetake $\mathrm{H}$, et al: The sex-determining locus in the tiger pufferfish, Takifugu rubripes. Genetics 175:2039-2042 (2007).

Kitano T, Takamune K, Nagahama Y, Abe SI: Aromatase inhibitor and 17alpha-methyltestosterone cause sex-reversal from genetical females to phenotypic males and suppression of p450 aromatase gene expression in Japanese flounder (Paralichthys olivaceus). Mol Reprod Dev 56:1-5 (2000).

-Kobayashi T, Kajiura-Kobayashi H, Nagahama Y: Differential expression of vasa homologue gene in the germ cells during oogenesis and spermatogenesis in a teleost fish, tilapia, Oreochromis niloticus. Mech Dev 99:139-142 (2000).

Kobayashi T, Kajiura-Kobayashi H, Nagahama $\mathrm{Y}$ : Two isoforms of vasa homologs in a teleost fish: their differential expression during germ cell differentiation. Mech Dev 111:167171 (2002).

Kobayashi T, Kajiura-Kobayashi H, Nagahama Y: Induction of XY sex reversal by estrogen involves altered gene expression in a teleost, tilapia. Cytogenet Genome Res 101:289-294 (2003).

- Kobayashi T, Matsuda M, Kajiura-Kobayashi H, Suzuki A, Saito N, et al: Two DM domain genes, $D M Y$ and $D M R T 1$, involved in testicular differentiation and development in the medaka, Oryzias latipes. Dev Dyn 231:518526 (2004).

Kobayashi Y, Sunobe T, Kobayashi T, Nagahama Y, Nakamura M: Gonadal structure of the serial-sex changing gobiid fish Trimma okinawae. Dev Growth Differ 47:7-13 (2005).

- Kobayashi Y, Nakamura M, Sunobe T, Usami T, Kobayashi T, et al: Sex change in the gobiid fish is mediated through rapid switching of gonadotropin receptors from ovarian to testicular portion or vice versa. Endocrinology 150:1503-1511 (2009).

Kobayashi Y, Horiguchi R, Miura S, Nakamura M: Sex- and tissue-specific expression of p450 aromatase (cyp19a1a) in the yellowtail clownfish, Amphiprion clarkii. Comp Biochem Phys A 155:237-244 (2010). 
- Kojima Y, Bhandari RK, Kobayashi Y, Nakamura M: Sex change of adult initial-phase male wrasse, Halichoeres trimaculatus by estradiol-17 beta treatment. Gen Comp Endocrinol 156:628-632 (2008).

Kondo M, Nanda I, Schmid M, Schartl M: Sex determination and sex chromosome evolution: insights from medaka. Sex Dev 3:88-98 (2009).

Koopman P, Loffler KA: Sex determination: the fishy tale of Dmrt1. Curr Biol 13:R177-R179 (2003).

Koopman P, Munsterberg A, Capel B, Vivian N, Lovell-Badge R: Expression of a candidate sex-determining gene during mouse testis differentiation. Nature 348:450-452 (1990).

Lee YH, Du JL, Yueh WS, Lin BY, Huang JD, et al: Sex change in the protandrous black porgy, Acanthopagrus schlegeli: a review in gonadal development, estradiol, estrogen receptor, aromatase activity and gonadotropin. J Exp Zool 290:715-726 (2001).

Maack G, Segner H: Morphological development of the gonads in zebrafish. J Fish Biol 62:895-906 (2003)

Manabe H, Ishimura M, Shinomiya A, Sunobe T: Field evidence for bi-directional sex change in the polygynous gobiid fish Trimma okinawae. J Fish Biol 70:600-609 (2007).

-Manabe H, Matsuoka M, Goto K, Dewa SI, Shinomiya $\mathrm{A}$, et al: Bi-directional sex change in the gobiid fish Trimma sp.: does size-advantage exist? Behaviour 145:99-113 (2008).

- Marshall Graves JA: The rise and fall of SRY. Trends Genet 18:259-264 (2002).

Matson CK, Murphy MW, Sarver AL, Griswold MD, Bardwell VJ, Zarkower D: DMRT1 prevents female reprogramming in the postnatal mammalian testis. Nature 476:101-104 (2011).

Matsuda M: Sex determination in fish: lessons from the sex-determining gene of the teleost medaka, Oryzias latipes. Dev Growth Differ 45:397-403 (2003).

Matsuda M, Nagahama Y, Shinomiya A, Sato T, Matsuda C, et al: Dmy is a Y-specific DMdomain gene required for male development in the medaka fish. Nature 417:559-563 (2002).

Matsuda M, Shinomiya A, Kinoshita M, Suzuki A, Kobayashi T, et al: Dmy gene induces male development in genetically female (XX) medaka fish. Proc Natl Acad Sci USA 104:38653870 (2007).

-Miura S, Nakamura S, Kobayashi Y, Piferrer F, Nakamura M: Differentiation of ambisexual gonads and immunohistochemical localization of P450 cholesterol side-chain cleavage enzyme during gonadal sex differentiation in the protandrous anemonefish, Amphiprion clarkii. Comp Biochem Physiol B Biochem Mol Biol 149:29-37 (2008).

- Murata R, Karimata H, Alam MA, Nakamura M: Gonadal sex differentiation in the Malabar grouper, Epinephelus malabaricus. Aquaculture 293:286-289 (2009).
Nagahama Y: Endocrine regulation of gametogenesis in fish. Int J Dev Biol 38:217-229 (1994).

Nagahama Y: Molecular mechanisms of sex determination and gonadal sex differentiation in fish. Fish Physiol Biochem 31:105-109 (2005).

Nakamoto M, Matsuda M, Wang DS, Nagahama Y, Shibata N: Molecular cloning and analysis of gonadal expression of Foxl2 in the medaka, Oryzias latipes. Biochem Bioph Res Commun 344:353-361 (2006).

- Nakamura M, Hourigan TF, Yamauchi K, Nagahama Y, Grau EG: Histological and ultrastructural evidence for the role of gonadal steroid hormones in sex change in the protogynous wrasse Thalassoma duperrey. Env Biol Fisher 24: 117-136 (1989).

- Nakamura M, Mariko T, Nagahama Y: Ultrastructure and in vitro steroidogenesis of the gonads in the protandrous clownfish Amphiprion frenatus. J Ichthyol 41:47-56 (1994).

- Nakamura M, Kobayashi T, Chang XT, Nagahama Y: Gonadal sex differentiation in teleost fish. J Exp Zool 281: 362-372 (1998)

- Nakamura M, Kobayashi Y, Miura S, Alam MA, Bhandari RK: Sex change in coral reef fish. Fish Physiol Biochem 31:117-122 (2005).

Nanda I, Kondo M, Hornung U, Asakawa S, Winkler C, et al: A duplicated copy of $d m r t 1$ in the sex-determining region of the $\mathrm{Y}$ chromosome of the medaka, Oryzias latipes. Proc Natl Acad Sci USA 99:11778-11783 (2002).

Nelson JS: Fishes of the World (4th ed.) (John Wiley \& Sons, Inc., New Jersey 2006).

Nozu R, Kojima Y, Nakamura M: Short term treatment with aromatase inhibitor induces sex change in the protogynous wrasse, Halichoeres trimaculatus. Gen Comp Endocrinol 161:360-364 (2009).

Oshima Y, Uno Y, Matsuda Y, Kobayashi T, Nakamura M: Molecular cloning and gene expression of Foxl2 in the frog Rana rugosa. Gen Comp Endocrinol 159: 170-177 (2008).

Paul-Prasanth B, Matsuda M, Lau EL, Suzuki A, Sakai F, et al: Knock-down of $D M Y$ initiates female pathway in the genetic male medaka, Oryzias latipes. Biochem Biophys Res Commun 351: 815-819 (2006).

-Paul-Prasanth B, Nakamura M, Nagahama Y: Sex determination in fishes, in David ON, Kristin HL (eds): Hormones and Reproduction of Vertebrates - Vol. 1, pp 1-14 (Academic Press, London 2011).

Peichel CL, Ross JA, Matson CK, Dickson M, Grimwood J, et al: The master sex-determination locus in threespine sticklebacks is on a nascent Y chromosome. Curr Biol 14:14161424 (2004).

Penman DJ, Piferrer F: Fish gonadogenesis. Part I: Genetic and environmental mechanisms of sex determination. Rev Fish Sci 16:16-34 (2008).

Piferrer F, Guiguen Y: Fish gonadogenesis. Part ii: Molecular biology and genomics of sex differentiation. Rev Fish Sci 16:35-55 (2008).
Piferrer F, Zanuy S, Carrillo M, Solar II, Devlin $\mathrm{RH}$, Donaldson EM: Brief treatment with an aromatase inhibitor during sex differentiation causes chromosomally female salmon to develop as normal, functional males. J Exp Zool 270:255-262 (1994).

Raghuveer K, Senthilkumaran B: Identification of multiple dmrt1s in catfish: localization, dimorphic expression pattern, changes during testicular cycle and after methyltestosterone treatment. J Mol Endocrinol 42:437448 (2009).

-Raghuveer K, Garhwal R, Wang DS, Bogerd J, Kirubagaran R, et al: Effect of methyl testosterone- and ethynyl estradiol-induced sex differentiation on catfish, Clarias gariepinus: expression profiles of DMRT1, Cytochrome P450aromatases and 3 $\beta$-hydroxysteroid dehydrogenase. Fish Physiol Biochem 31:143-147 (2005).

Raghuveer K, Senthilkumaran B, Sudhakumari CC, Sridevi P, Rajakumar A, et al: Dimorphic expression of various transcription factor and steroidogenic enzyme genes during gonadal ontogeny in the air-breathing catfish, Clarias gariepinus. Sex Dev 5:213-223 (2011).

Raymond CS, Shamu CE, Shen MM, Seifert KJ, Hirsch B, et al: Evidence for evolutionary conservation of sex-determining genes. Nature 391:691-695 (1998).

Ruksana S, Pandit NP, Nakamura M: Efficacy of exemestane, a new generation of aromatase inhibitor, on sex differentiation in a gonochoristic fish. Comp Biochem Physiol C Toxicol Pharmacol 152:69-74 (2010).

-Sakai F, Kobayashi T, Matsuda M, Nagahama Y: Stability in aromatase immunoreactivity of steroid-producing cells during early development of XX gonads of the Nile tilapia, Oreochromis niloticus: an organ culture study. Zool Sci 25:344-348 (2008).

- Sawatari E, Shikina S, Takeuchi T, Yoshizaki G: A novel transforming growth factor-beta superfamily member expressed in gonadal somatic cells enhances primordial germ cell and spermatogonial proliferation in rainbow trout (Oncorhynchus mykiss). Dev Biol 301: 266-275 (2007).

-Schlessinger D, Garcia-Ortiz JE, Forabosco A, Uda M, Crisponi L, Pelosi E: Determination and stability of gonadal sex. J Androl 31:1625 (2010).

- Ser JR, Roberts RB, Kocher TD: Multiple interacting loci control sex determination in Lake Malawi cichlid fish. Evolution 64:486-501 (2010).

-Shibata Y, Paul-Prasanth B, Suzuki A, Usami T, Nakamoto M, et al: Expression of gonadal soma derived factor (GSDF) is spatially and temporally correlated with early testicular differentiation in medaka. Gene Expr Patterns 10:283-289 (2010) 
-Shirak A, Seroussi E, Cnaani A, Howe AE, Domokhovsky R, et al: Amh and Dmrta2 genes map to tilapia (Oreochromis spp.) linkage group 23 within quantitative trait locus regions for sex determination. Genetics 174 : 1573-1581 (2006).

- Sinclair AH, Berta P, Palmer MS, Hawkins JR, Griffiths BL, et al: A gene from the human sex-determining region encodes a protein with homology to a conserved DNA-binding motif. Nature 346:240-244 (1990).

-Strüssmann CA, Nakamura M: Morphology, endocrinology, and environmental modulation of gonadal sex differentiation in teleost fishes. Fish Physiol Biochem 26:13-29 (2002).

-Sudhakumari CC, Senthilkumaran B, Kobayashi T, Kajiura-Kobayashi H, Wang DS, et al: Ontogenic expression patterns of several nuclear receptors and cytochrome P450 aromatases in brain and gonads of the Nile tilapia Oreochromis niloticus suggests their involvement in sex differentiation. Fish Physiol Biochem 31:129-135 (2005).

Sunobe T, Nakazono A: Polygynous mating system of Trimma okinawae (pisces: Gobiidae) at Kagoshima, Japan with a note on sex change. Ethology 84:133-143 (1990).
Sunobe T, Nakazono A: Sex change in both directions by alteration of social dominance in Trimma okinawae (pisces: Gobiidae). Ethology 94:339-345 (1993).

Tripathi N, Hoffmann M, Weigel D, Dreyer C: Linkage analysis reveals the independent origin of poeciliid sex chromosomes and a case of atypical sex inheritance in the guppy (Poecilia reticulata). Genetics 182:365-374 (2009).

-Uhlenhaut NH, Jakob S, Anlag K, Eisenberger T, Sekido R, et al: Somatic sex reprogramming of adult ovaries to testes by Foxl2 ablation. Cell 139:1130-1142 (2009).

Vizziano D, Randuineau G, Baron D, Cauty C, Guiguen Y: Characterization of early molecular sex differentiation in rainbow trout, $\mathrm{On}$ corhynchus mykiss. Dev Dyn 236:2198-2206 (2007).

Volff JN, Nanda I, Schmid M, Schartl M: Governing sex determination in fish: regulatory putsches and ephemeral dictators. Sex Dev 1: 85-99 (2007).

-Wang DS, Kobayashi T, Zhou L, Nagahama Y: Molecular cloning and gene expression of Foxl2 in the Nile Tilapia, Oreochromis niloticus. Biochem Biophys Res Commun 320:8389 (2004).
Wang DS, Kobayashi T, Zhou LY, Paul-Prasanth B, Ijiri S, et al: Foxl2 up-regulates aromatase gene transcription in a female-specific manner by binding to the promoter as well as interacting with Ad4 binding protein/steroidogenic factor 1. Mol Endocrinol 21:712725 (2007).

-Wang DS, Zhou LY, Kobayashi T, Matsuda M, Shibata Y, et al: Doublesex- and mab-3-related transcription factor-1 repression of aromatase transcription, a possible mechanism favoring the male pathway in tilapia. Endocrinology 151:1331-1340 (2010).

- Yamaguchi T, Yamaguchi S, Hirai T, Kitano T: Follicle-stimulating hormone signaling and Foxl2 are involved in transcriptional regulation of aromatase gene during gonadal sex differentiation in Japanese flounder, Paralichthys olivaceus. Biochem Biophys Res Commun 359:935-940 (2007).

Yamamoto T: Artificial induction of functional sex-reversal in genotypic females of the medaka (Oryzias latipes). J Exp Zool 137:227263 (1958).

Yao HH: The pathway to femaleness: current knowledge on embryonic development of the ovary. Mol Cell Endocrinol 230:87-93 (2005).

Zhang J, Chiodini R, Badr A, Zhang G: The impact of next-generation sequencing on genomics. J Genet Genomics 38:95-109 (2011). 